\title{
Triple oxygen and hydrogen isotopic variations of pore waters from the middle Bengal Fran (IODP Exp. 354)
}

\section{A. GALY'}

Université de Lorraine, Centre de Recherche Pétrographiques et Géochimiques (CRPG), Nancy, France.agaly@crpg.cnrs-nancy.fr

At the transect of the 7 drill sites of the IODP Expedition 354 , at $8^{\circ} \mathrm{N}$ across the Bengal Fan, the interstitial water chemistry displays systematic changes found at every sites, and similar to pore water profiles in other deep sea fans. In the top 30 to $60 \mathrm{~m}$, large rise in alkalinity is associated with the complete reduction of sulphate. A consequence of high alkalinity values is some consumption of calcium (and magnesium) induced by the precipitation of carbonate.

Variations in the $\mathrm{H} 2 \mathrm{O}$ isotopic compositions have been obtained by TDLAS using a modified Picarro L2140i. Pseudo bracketing with distilled waters have been used to correct for drift related to the progressive deposition of salt in the evaporation chamber, where an insert with $\mathrm{Ni}$ wool focussed the precipitation at the entrance of the chamber. With such protocol, no significant effect of salinity (up to 40\%) on the isotope analysis has been found and the external precisions were $0.6 \%, 0.08 \%$ and 19 per meg on $\delta \mathrm{D}, \delta 18 \mathrm{O}$ and $\Delta 17 \mathrm{O}$, respectively, at $2 \sigma$ level. The $\delta 180$ display a classical selfdiffusion of the water-molecule profiles with a rise of up to $0.50 \%$ and maximum values reached between 20 to $30 \mathrm{~m}$ depth below sea floor (mbsf). This is associated with a rise in salinity by up to $4 \%$, followed by a small decrease $(1.6 \%)$ in the next 50 to $100 \mathrm{~m}$. Below $30 \mathrm{mbsf}$, the $\delta 180$ profiles are characterised by a monotonous decrease, reaching a minimum of $-1.3 \%$ around 600 mbsf. Up to this depth, the $\delta D$ profiles are mimicking the $\delta 180$ profiles. Despite some isotopic modification (evaporation) during the sampling and the preservation, the bottom parts of the 2 deepest holes suggest a slight $(0.4 \%)$ rise of the $\delta 180$ associated with a decrease in the $\delta \mathrm{D}$ of $1.3 \%$. Deep diagenetic hydration reactions could explain such diverging trend in $\delta \mathrm{D}$ and $\delta 18 \mathrm{O}$, but would only correspond to a loss of $\mathrm{H} 2 \mathrm{O}$ to the sediment by no more than $1-2 \%$. The diversity of biogeochemical processes along those profiles is not impacting the $\Delta 17 \mathrm{O}$ since its average value of $1.4 \pm 17$ per meg $(2 \sigma, \mathrm{N}=159)$ on the VSMOW-VSLAP scale is very close to the $\Delta 17 \mathrm{O}$ of seawater and the variablility is smaller than the long term precision. In detail, however, they might be a slight increase ( $\sim 7$ per meg) in the $\Delta 17 \mathrm{O}$ in the top 300 mbsf, followed by a decrease of $\sim 15$ per meg between 300 and $750 \mathrm{mbsf}$ and another decrease of 12 per meg in the bottom 300 mbsf. 